\title{
Metode "King of Brama" sebagai pengembangan inovasi masa endemi komunitas Sambel Pecel Klegen Kota Madiun
}

\author{
Anggi Cahya Kharisma ${ }^{1}$, Puji Nurhayati ${ }^{1 *}$ \\ ${ }^{1}$ Program Studi Akuntansi, Fakultas Ekonomi dan Bisnis, Universitas PGRI Madiun \\ ${ }^{*}$ Korespondensi (e-mail: pujinurhayati@unipma.ac.id)
}

Received: 09-December-21; Revised: 31-December-21; Accepted: 31-December-21

\begin{abstract}
People's lives today cannot be separated from the existence of Micro Small and Medium Enterprises (MSMEs). The role of MSMEs is considered significant to the improvement of the Indonesian economy and is also able to absorb labor on a considerable scale. The problems faced by MSMEs today are marketing, branding and packaging. Likewise, with the problems faced by the Sambel Pecel community of Klegen village of Madiun city. Digital marketing is very important and crucial that must be done in order to compete in the global market. The purpose of this training is to provide innovation in product packaging or build a more modern brand to the MSMEs community Sambel Pecel Kota Madiun, as an increase in sales turnover during the covid-19 pandemic. The implementation method is carried out using several stages, namely 1 ) identifying the problem, 2) identifying the output, and 3) conducting training. The result of this activity is the innovation of Sambel Pecel products that have more modern packaging and branding. This activity is expected to make the Sambel Pecel MSME community develop and improve its marketing methods by using digital marketing.
\end{abstract}

Keywords: Digital marketing, Branding, Packaging

\begin{abstract}
Abstrak
Kehidupan masyarakat saat ini tidak dapat dipisahkan dengan keberadaan kegiatan Usaha Mikro Kecil dan Menengah (UMKM). Peran UMKM dianggap signifikan terhadap peningkatan perekonomian Indonesia dan juga mampu menyerap tenaga kerja dalam skala yang cukup besar. Permasalahan yang dihadapi oleh UMKM saat ini adalah marketing, branding dan packaging. Begitu juga dengan permasalahan yang dihadapi oleh komunitas sambel pecel kelurahan klegen kota madiun. Digital marketing sangat penting dan krusial yang harus dilakukan agar dapat bersaing di pasar global. Tujuan dari pelatihan ini adalah untuk memberikan inovasi dalam pengemasan produk atau membangun brand yang lebih modern kepada para komunitas UMKM sambel pecel Kota Madiun sebagai peningkatan omzet penjualan selama masa pandemic covid-19. Metode pelaksanaan dilakukan dengan menggunakan beberapa tahap yaitu 1) identifiaksi masalah, 2) identifikasi output, dan 3) melakukan pelatihan. Hasil kegiatan ini adalah inovasi produk sambel pecel yang memiliki packaging dan branding yang lebih modern. Kegiatan ini diharapkan menjadikan komunitas UMKM Sambel Pecel berkembang dan memperbaiki metode pemasarannya dengan menggunakan digital marketing.

Kata kunci: Digital marketing, Branding, Packaging

How to cite: Kharisma, A. C., \& Nurhayati, P. (2021). Metode "King of Brama" sebagai pengembangan inovasi masa endemi Komunitas Sambel Pecel klegen Kota Madiun. Penamas: Journal of Community Service, 1(2), 125-135. https://doi.org/10.53088/penamas.v1i2.222
\end{abstract}




\section{Pendahuluan}

Demokrasi ekonomi dapat mewujudkan pembangunan perekonomian nasional yang mandiri dan handal untuk meningkatkan kemakmuran ekonomi secara selaras, adil, dan merata. Sasaran untuk mencapai keseimbangan antara bidang pertanian dan bidang industri serta terpenuhinya kebutuhan pokok rakyat (Luckyta Sari \& Oktovita Sari, 2021). Kehidupan masyarakat saat ini tidak dapat dipisahkan dengan keberadaan kegiatan Usaha Mikro Kecil dan Menengah (UMKM). Peran UMKM dianggap signifikan terhadap peningkatan perekonomian Indonesia dan juga mampu menyerap tenaga kerja dalam skala yang cukup besar (Maulida Sari \& Setiyana, 2020) Menurut Hartono dan Dwi(2014) dalam (Maulida Sari \& Setiyana, 2020)diperkirakan sebagian besar para pelaku UMKM bergerak pada sektor konvensional dan berperan penting dalam perekonomian di Indonesia. Hal ini memanifestasikan bahwa tenaga kerja yang tidak berhasil diserap oleh sektor formal akan bergesar ke sektor konvensional.

Sektor Usaha Mikro Kecil Menengah (UMKM) pada kenyataanya mampu meningkatkan kinerja yang lebih unggul dalam menghadapi masa krisis. Pada masamasa krisis perekonomian yang terjadi beberapa tahun yang lalu, Indonesia terselamatkan oleh kestabilan kegiatan usaha mikro kecil dan menengah. Hal ini terbukti bahwa segmen usaha tersebut mampu mengadaptifkan perubahan bahkan saat krisis ekonomi sekalipun. Usaha mikro kecil dan menengah (UMKM) merupakan bagian dari perekonomian kerakyatan dengan jumlah sektor yang cukup dominan. Sehingga UMKM mampu mempengaruhi dalam perekonomian nasional (Luckyta Sari \& Oktovita Sari, 2021).

Pada perkembangan masa saat ini, persaingan antara wirausaha maupun UMKM dengan pesaing (competitor) semakin ketat, sehingga pelaku UMKM harus melakukan strategi inovasi pada berbagai faktor pada produknya, khusus nya pada faktor pemasaran. Faktor pemasaran terhadap pemasaran produk yang dihasilkan oleh perusahaan dan wirausaha, para pelaku perlu mengenal marketing mix. Menurut Kotler \& Keller (2009) marketing mix adalah rangkaian alat pemasaran khusus digunakan perusahaan dan wirausaha, yang terdiri dari produk, harga, promosi, dan tempat atau distribusi.

Perkembangan sektor agroindustri yang banyak dijumpai dikalangan masyarakat kecil yaitu industri rumahan. Industri ini merupakan perusahaan kecil milik perseorangan yang dikelola sendiri. Pemilik nya ini mempunyai tanggung jawab dan berkuasa penuh terhadap pengelolaan dan pengendalian penjualannya. Tanggung jawab tersebut dimaksudkan bahwa pemilik bertanggung jawab atas kewajiban utangutang nya dengan mengorbankan modal untuk usaha nya tersebut dengan seluruh milik pribadinya (Luckyta Sari \& Oktovita Sari, 2021).

Salah satu kota di Indonesia yang memiliki agroindustry yang cukup pesat di daerah nya yaitu Kota Madiun. Dimana perkembangan industry nya kebanyakan pada sektor kuliner yakni yang paling terkenal Pecel Land Madiun. Mulai dari industry berskala besar hingga ke skala kecil daya saing sambel pecel sangat tinggi terjadi di sekitar 
para UMKM sambel pecel. Asal nama Pecel dapat dimaknai secara etimologi dalam Bahasa Jawa, bahwa pecel dapat diartikan sebagai 'tumbuk' atau 'dihancurkan dengan cara ditumbuk'(id.m.wikipedia.org).

Kota Madiun memiliki 23.454 UMKM yang terdiri dari 9 sektor, salah satunya adalah UMKM sambel pecel. Sambel pecel merupakan produk unggulan karena banyak nya peminat atau pecinta nasi pecel di sekitaran daerah karasidenan Madiun bahkan sampai ke luar negeri. Hal itulah yang memungkinkan banyak pelaku UMKM untuk memproduksi sambel pecel untuk dijual dikalangan pasar-pasar tradisional. Penjual sambel pecel sangat banyak, mulai dari yang dijual dalam jumlah kecil, hingga ada yang dijual dalam jumlah yang besar. Walaupun demikian, sambel pecel dalam segi pengemasannya masih menggunakan plastic maupun mika. Dari sisi pemasaran, juga masih menggunakan metode konvensional yaitu door to door. Dari sisi branding, mayoritas sambel pecel kota madiun yang dipasarkan belum ada yang mencantumkan merk ataupun brand. Hal ini dikarenakan para pelaku UMKM sambel pecel di Madiun saat ini masih kurang pengetahuan tentang pentingnya pengaruh packaging, branding, dan marketing atau yang disingkat dengan "King of Brama".

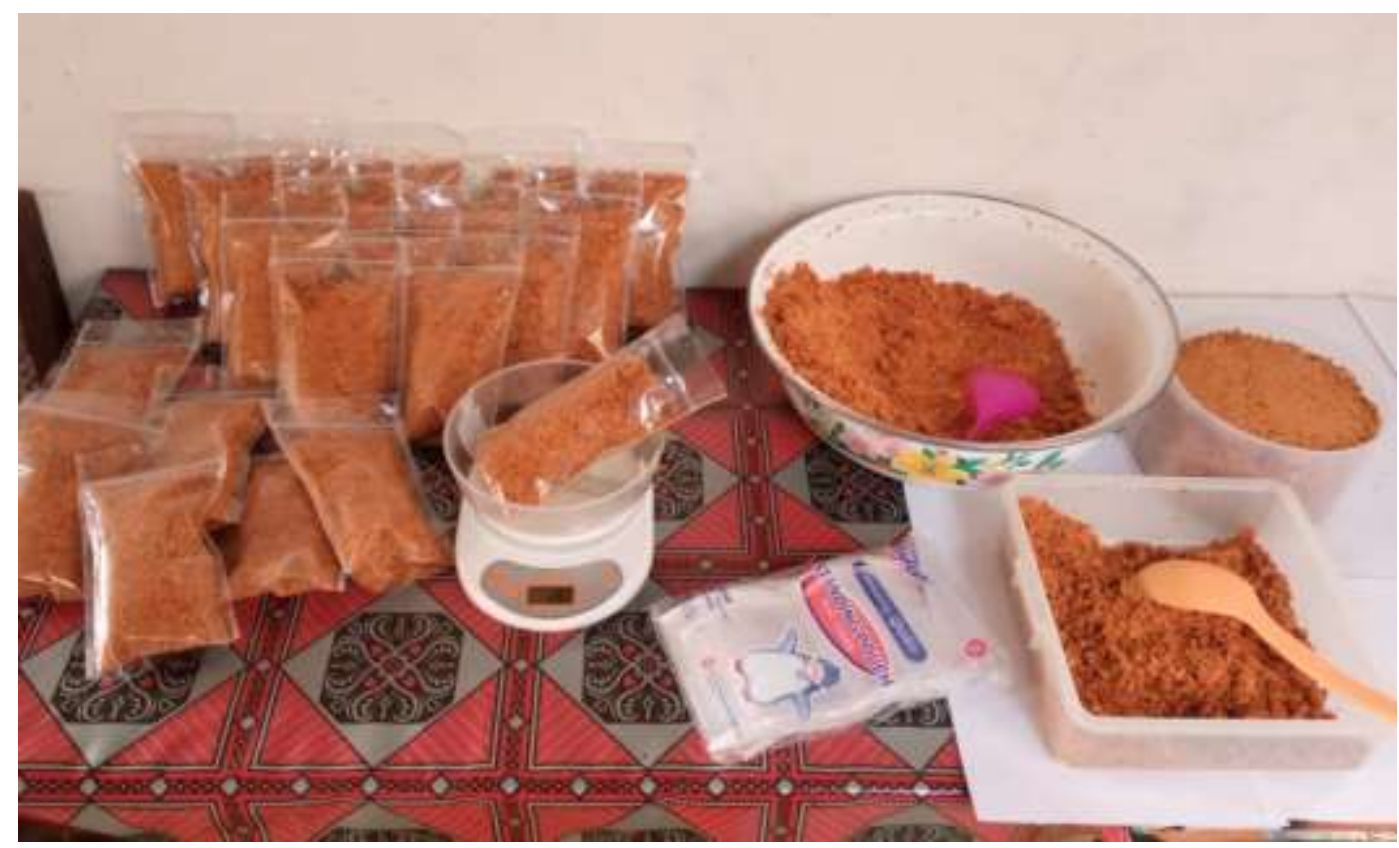

Gambar 1. Proses Pengemasan Sambel Pecel

Sebelumnya tim pengabdi sudah melakukan survey ke mitra untuk mengetahui proses produksi dan pengemasan sambel pecel klegen Kota Madiun. Berikut adalah proses pengemasan sambel pecel yang sudah dilakukan oleh mitra:

Dalam pengemasan ada yang menggunakan plastic dan ada yang menggunakan mika, hal ini dilakukan karena pemasaran hanya dilakukan dalam kota madiun dan maksimal hanya dititipkan di toko oleh-oleh kota madiun. Berikut adalah contoh pengemasan yang sudah dilakukan oleh mitra: 


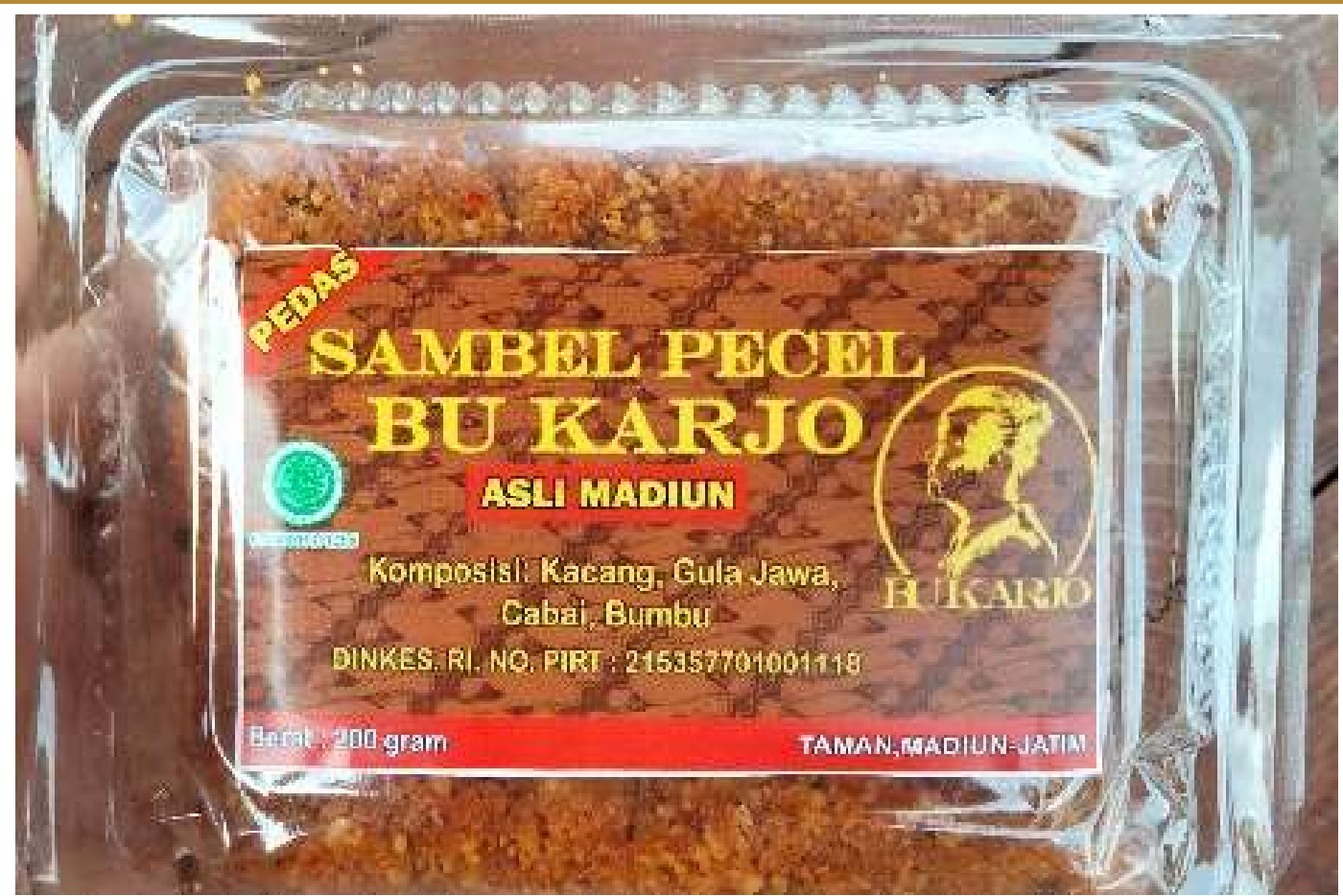

Gambar 2. Pengemasan Menggunakan Mika

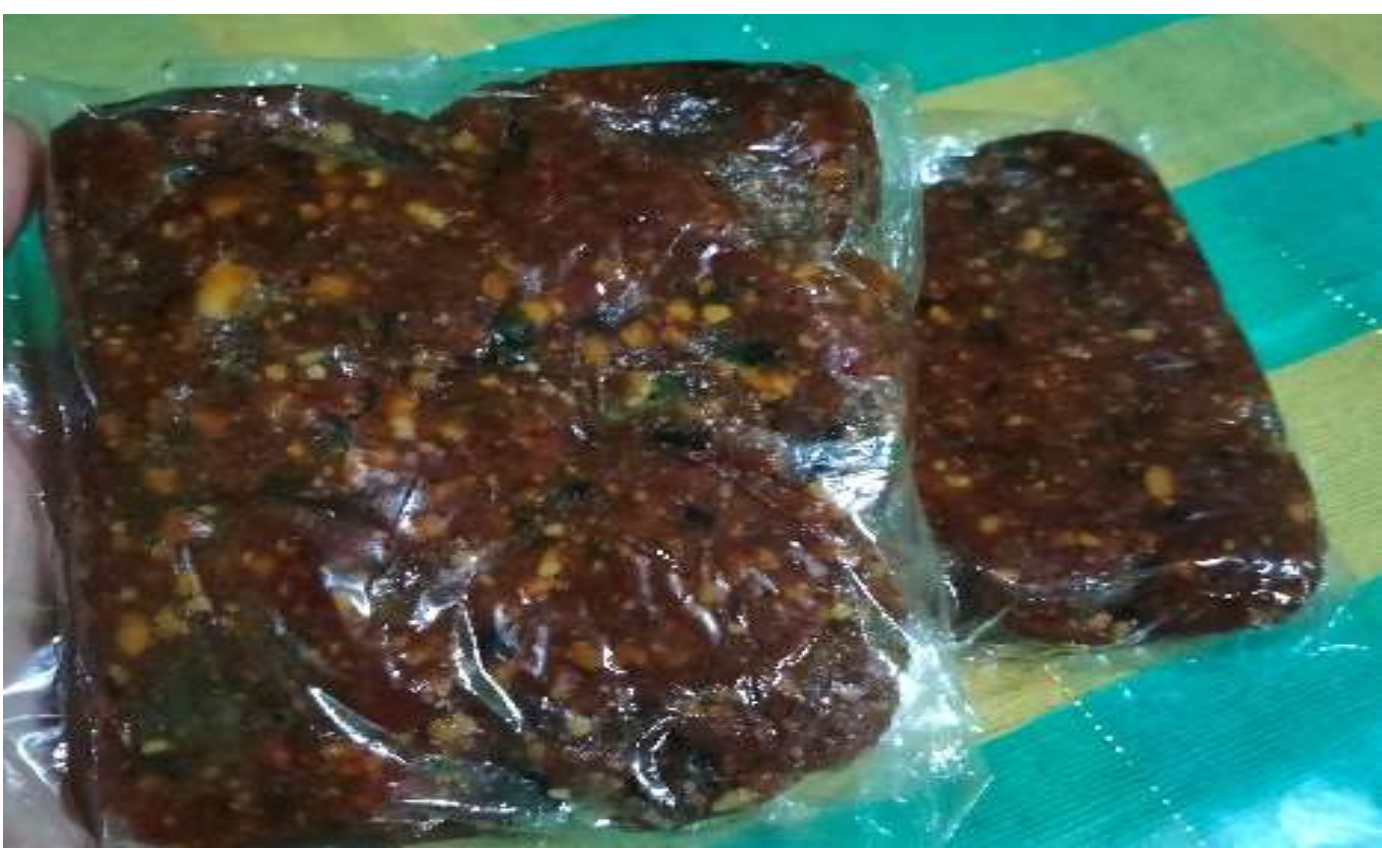

Gambar 3. Pengemasan Menggunakan Plastik

Maka dari itu, komunitas UMKM sambel pecel di Klegen Kecamatan Kartoharjo Kota Madiun menjadi sasaran utama dalam program ini. Komunitas UMKM sambel pecel di Klegen memiliki anggota lebih dari 10 orang. Dengan adanya program ini tim pengabdi akan melakukan pengabdian masyarakat untuk meningkatkan pengetahuan pelaku UMKM mengenai packaging, branding, dan marketing agar dapat meningkatkan penjualan. Hal ini tentunya berguna untuk keberlangsungan para komuunitas sambel pecel agar dapat meningkatkan keuntungan lebih besar di masa endemic. Selain itu, juga sebagai upaya peningkatan pengetahuan para komunitas pelaku UMKM dimasa pandemic ini di Kota Madiun. 


\section{Metode Pengabdian}

Metode pelaksanaan ini menjelaskan tentang kegiatan Pengabdian Masyarakat mengenai tahapan pelaksanaan yang dilakukan di UMKM Sambel Pecel Madiun. Ada 3 tahapan dalam pelaksanaan yaitu sebagai berikut:

\section{Persiapan,}

Langkah-langkah yang dilakukan dalam persiapan ini adalah

a. Tim menggali informasi permasalahan yang ada pada mitra dengan menjalin komunikasi untuk menyatukan pendapat sehingga dapat merumuskan masalah pada mitra,

b. Tim pelaksana mempersiapkan administrasi terkait dengan perijinan dan surat tugas melalui lembaga penelitian pengabdian kepada masyarakat,

c. Mempersiapkan Tim pelaksana untuk membantu pelaksanaan kegiatan. Tim pelaksana akan dilibatkan dalam tutorial dan pelatihan, pemantauan perkembangan mitra dan dokumentasi secara daring maupun luring.

\section{Pelaksanaan kegiatan}

a. Penyampaian materi tentang pengetahuan packaging, branding, marketing kepada komunitas sambel pecel Klegen Kota Madiun.

b. Penyampaian tutorial mengenai pengemasan menggunakan metode King of Brama.

c. Pelatihan dan pembimbingan dilakukan secara daring maupun luring. Pelatihan dan pembimbingan program dilakukan secara kontinyu 2 kali dalam seminggu. Sedangkan untuk kegiatan konsultasi mengenai kemajuan produk para komunitas sambel pecel dilakukan melalui whatsapp group dan via zoom/gmeet. Teknis marketing yang akan dilakukan dengan mengikutsertakan pada market place untuk memudahkan calon customer dalam melakukan pembelian.

\section{Pemantauan}

Pemantau meliputi pemantauan kerjasama mitra dengan pemasok bahan baku dan pengecer sambel pecel, pemantauan terhadap pengembangan inovasi produk pada kemampuan para komunitas UMKM sambel pecel mendesain merk, label, dan pemasaran dengan menggunakan market place.

\section{Evaluasi}

Evaluasi meliputi evaluasi terhadap kemampuan tiap komunitas sambel pecel menjalin kerjasama dengan pemasok dan pengecer, evaluasi tentang kemampuan komunitas sambel pecel meningkatkan kualitas produk dan daya tahan produk, evaluasi terhadap keberadaan merek, label dan kemasan, evaluasi terhadap kegiatan promosi yang dilakukan oleh komunitas sambel pecel. Promosi yang kita gunakan mungkin lebih menggunakan via sosial media seperti whatsapp, facebook, Instagram, serta market place seperti shopee yang lebih banyak pengguna ataupun peminatnya. 


\section{Hasil Pengabdian}

Kegiatan pengabdian masyarakat diawali dengan survey ke komunitas sambel pecel di Klegen kota Madiun pada tanggal 1 Desember 2021. Survey dilakukan untuk menggali informasi berkaitan dengan jumlah UMKM, metode pemasaran, strategi branding dan metode packaging sambel pecel yang selama ini dilakukan. Berdasarkan informasi yang didapatkan, anggota komunitas sambel pecel berjumlah 15 orang yang aktif. Berikut dokumentasi dari kegiatan survey:

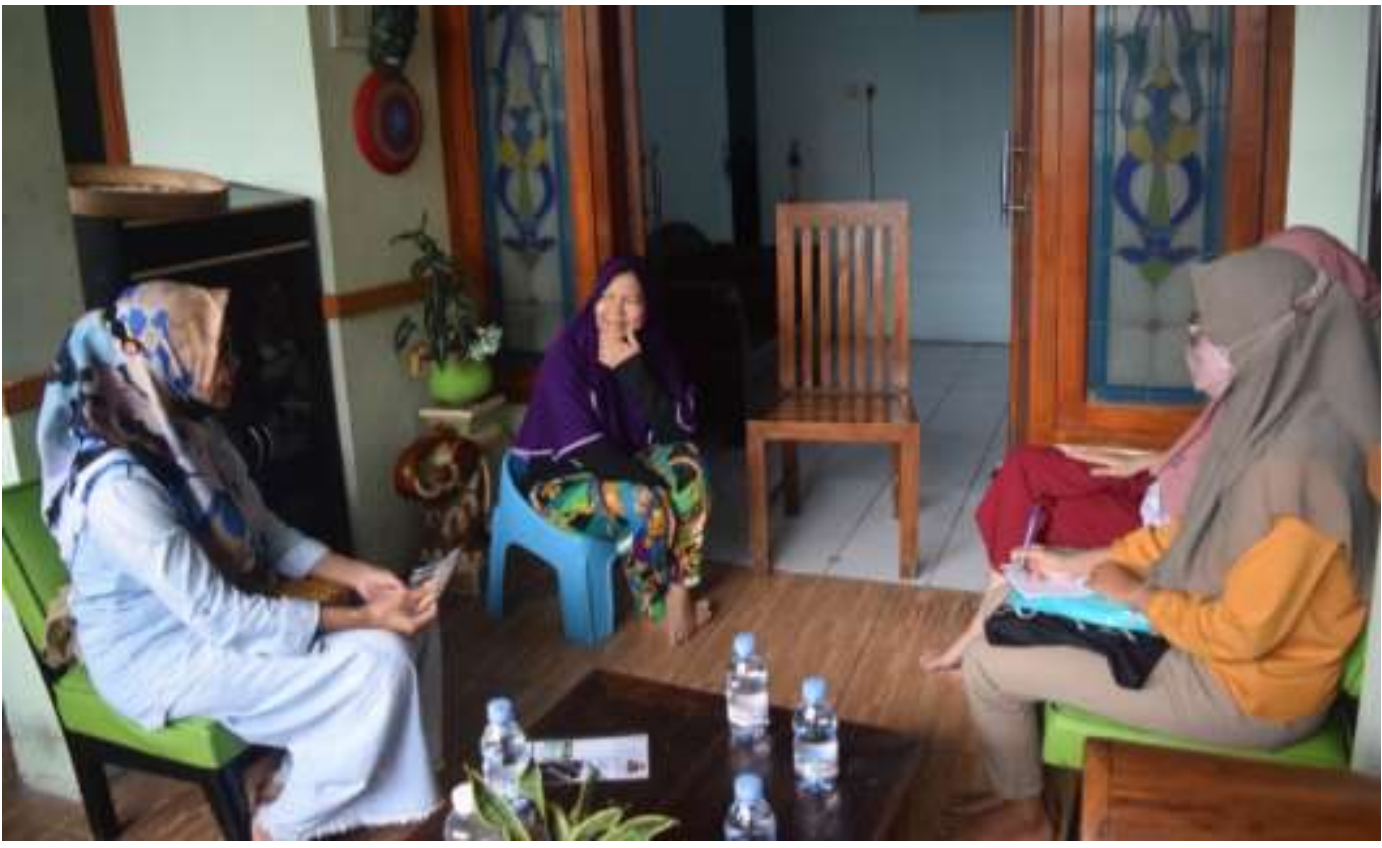

Gambar 4. Survey UMKM Komunitas sambel pecel

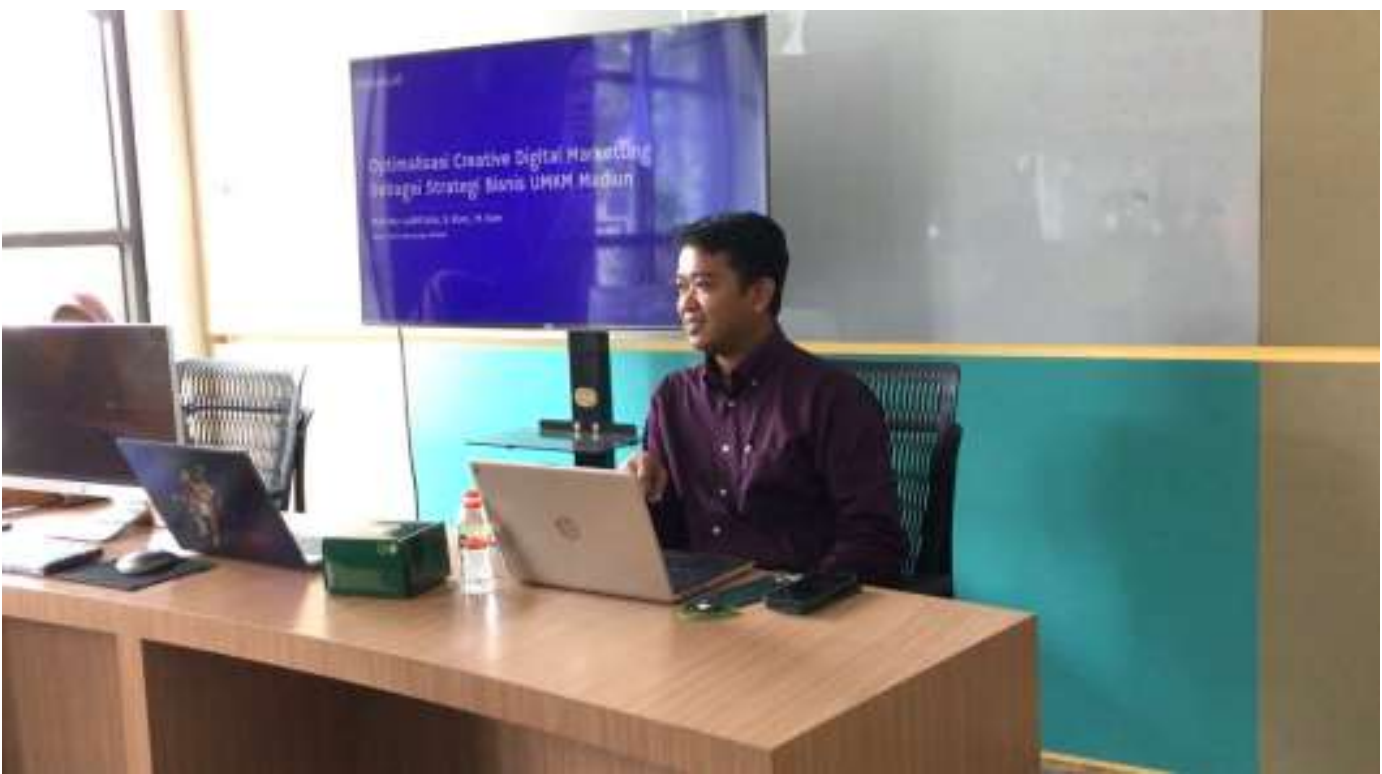

Gambar 5. Pemaparan materi digital marketing

Setelah survey dilakukan, tim pengabdian masyarakat mempersiapkan surat-surat administrasi meliputi surat permohonan narasumber, surat peminjaman tempat, surat undangan UMKM Komunitas sambel pecel dan daftar hadir workshop. Setelah itu, tim 
pengabdian masyarakat melakukan kegiatan workshop yang dilaksanakan dengan 3 sesi yaitu 1) digital marketing, 2) strategi branding dan 3) packaging.

Pengabdian masyarakat dilakukan secara bertahap dimulai dengan adanya workshop digital marketing, strategi branding, dan packaging. Kegiatan workshop digital marketing dilakukan tanggal 6 desember 2021 EJSC Bakorwil Kota Madiun dengan narasumber Muh. Nur Lutfi Aziz, S.Kom., M.Kom. Kegiatan ini mengangkat tema "Optimalisasi Creative Digital Marketing Sebagai Strategi Bisnis Umkm Sambel Pecel Madiun" yang diikuti oleh 10 UMKM dari komunitas sambel pecel Klegen Kota Madiun. tujuan dari kegiatan ini untuk meningkatkan pangsa pasar, jangkauan lebih luas, murah dan efektif. Selain itu, sekarang sudah era revolusi indutri 4.0 sehingga semua transaksi sudah menggunakan teknologi agar dapat masuk ke pasar global. Berikut adalah dokumentasi kegiatan workshop digital marketing:

Hasil dari kegiatan pemaparan materi dari marketing yaitu pemasaran produk dengan menggunakan media sosial seperti facebook, Instagram, dan grup whatsapp dapat menunjang minat pembeli. Selain media sosial, market place juga menunjang pemasaran produk seperti shopee, lazada, toko pedia, dan lain-lain yang dapat meningkatkan omset penjualan. Pada era saat ini banyak pengusaha yang beralih bisnis ke bidang kuliner. Diharapkan dengan adanya materi mengenai marketing ini para UMKM dapat berupaya untuk meningkatkan strategi pemasaran produk milik mereka.

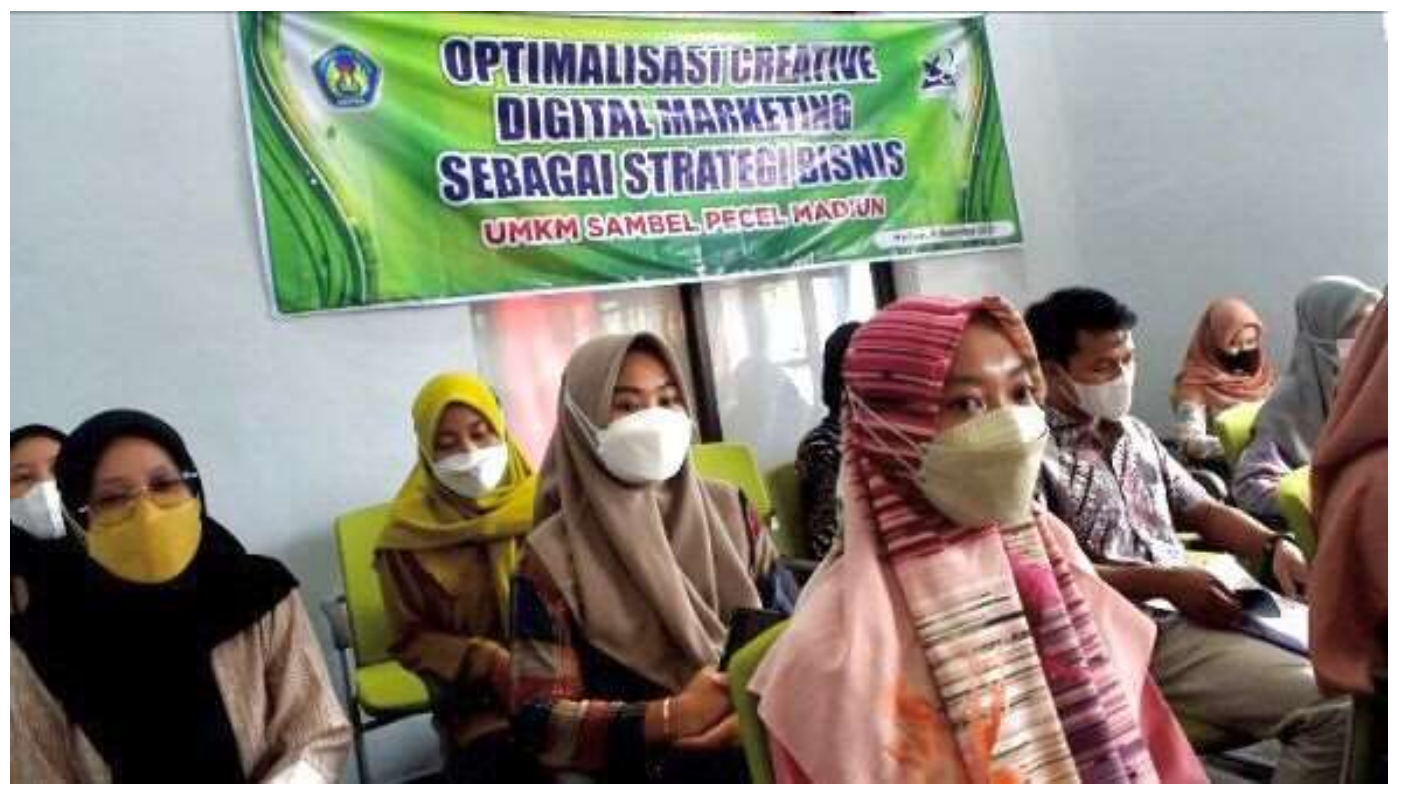

Gambar 6. Peserta workshop digital marketing UMKM komunitas sambel pecel

Kegiatan pengabdian masyarakat yang kedua yaitu workshop menegenai packaging. Workshop tersebut dilakukan pada tanggal 7 Desember 2021 di EJSC Bakorwil Kota Madiun dengan narasumber Anggi Cahya dan Alfina dari Universitas PGRI Madiun. Kegiatan ini mengangkat tema tentang "Smart Packaging Pada Umkm Sambel Pecel Madiun" dengan peserta 12 UMKM. Kegiatan ini dilakukan dengan tujuan untuk untuk dapat menjaga serta lebih meningkatkan mutu pangan modern 
yang ada di Indonesia dalam memasuki pasar global. Berikut beberapa dokumentasi kegiatan packaging produk sambel pecel Madiun:

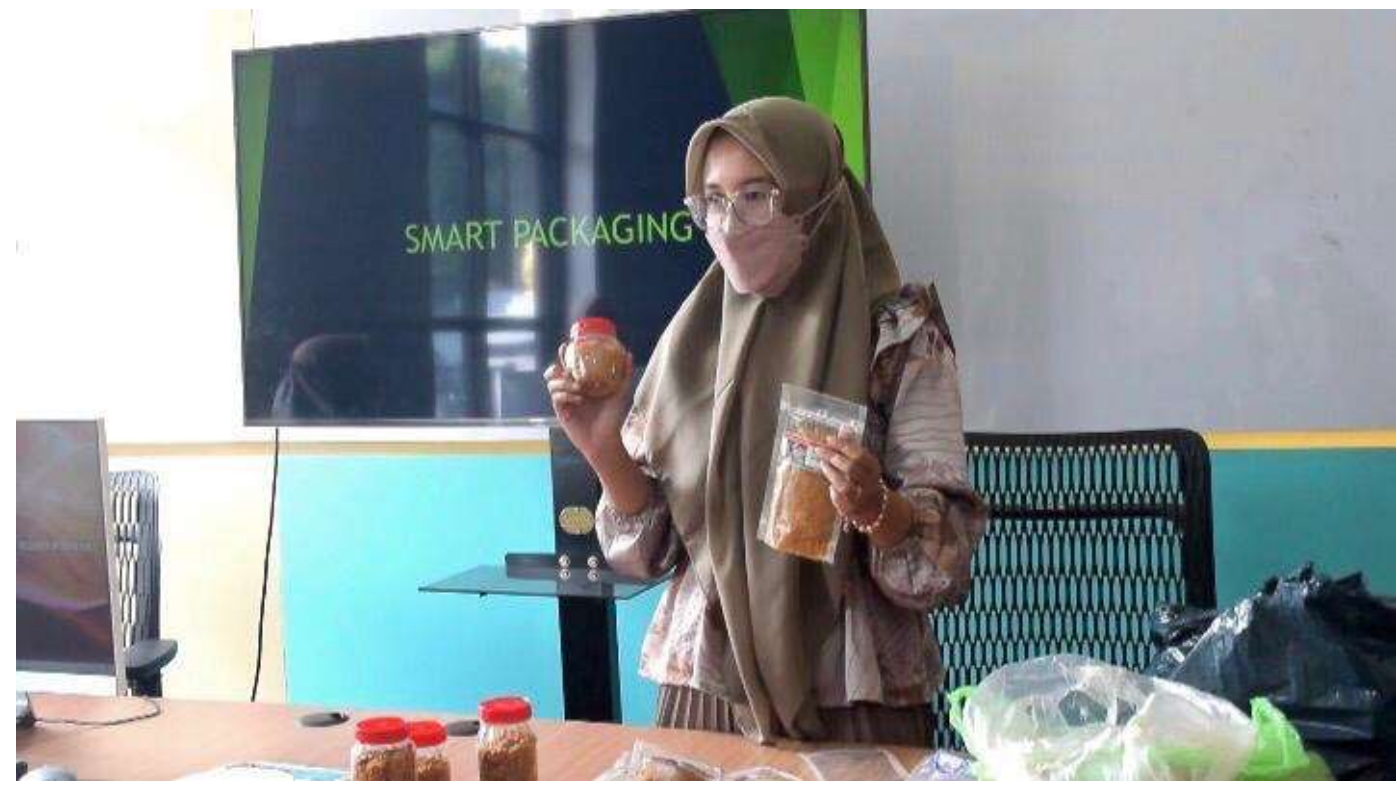

Gambar 7. Penjelasan mengenai smart packaging

Hasil dari pemaparan materi dan pelatihan packaging disini yaitu dijelaskan mengenai pengertian smart packaging. Keuntungan adanya smart packaging adalah relative terhadap harga produk yang dikemas, ramah lingkungan, mempunyai nilai estetika yang dapat diterima oleh system distribusi. Pelatihan disini juga mempraktekkan bagaimana pengemasan packaging dengan menggunakan cup botol dan plastic vacum sealer yang diberi stiker label sesuai ide brand yang dimiliki UMKM sambel pecel.

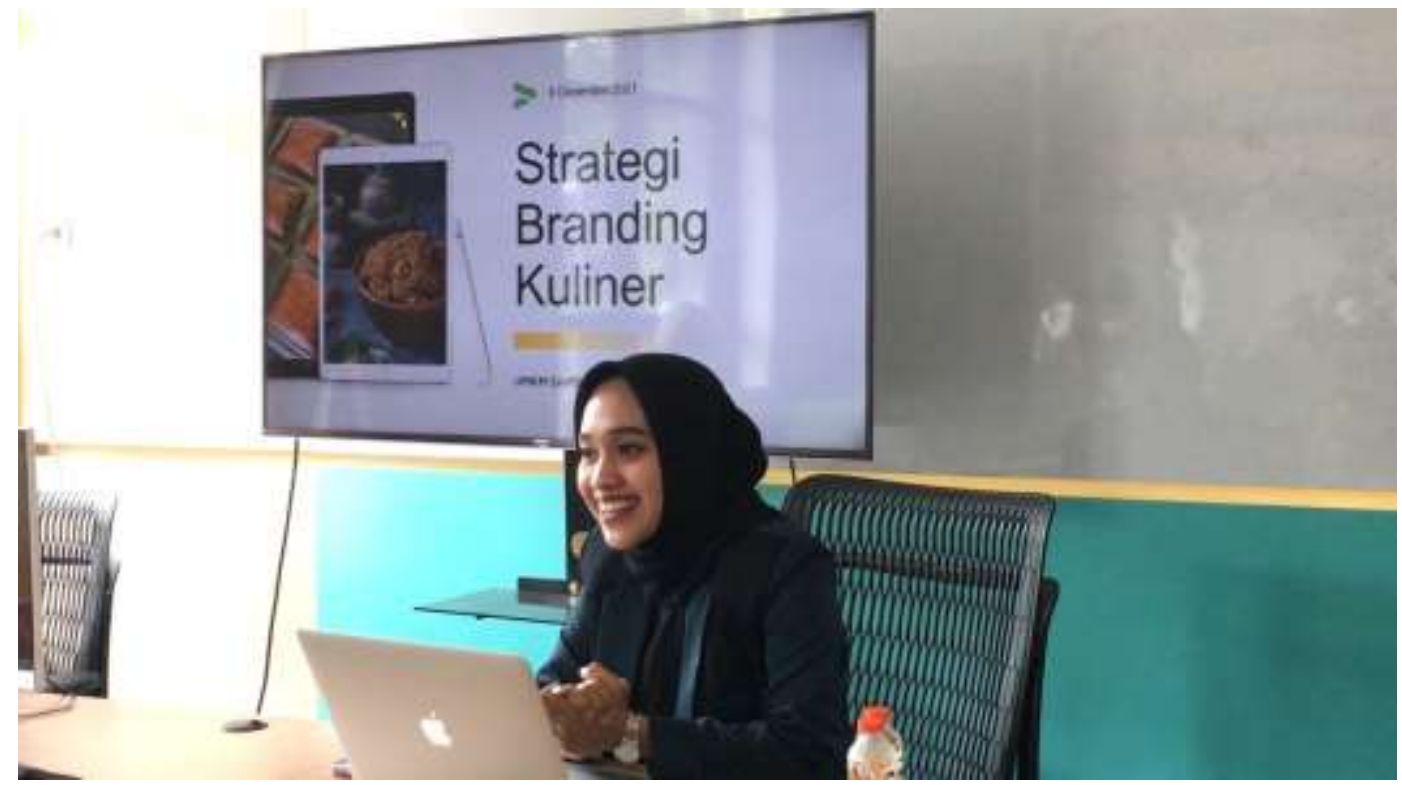

Gambar 8. Pemaparan materi tentang strategi branding

Kegiatan pengabdian masyarakat yang ketiga yaitu workshop strategi branding. Workshop strategi branding dilakukan pada tanggal 8 Desember 2021 di EJSC Bakorwil Kota Madiun dengan narasumber Afrisa Maya dari komunitas Career Light 
Kota Madiun. Kegiatan ini mengangkat tema tentang "Strategi Branding Dalam Mempertahankan Eksistensi Produk Sambel Pecel Madiun" dengan peserta 12 UMKM. Kegiatan ini dilakukan dengan tujuan untuk membentuk persepsi masyarakat, membangun rasa percaya masyarakat kepada brand dan membangun rasa cinta masyarakat kepada brand. Beberapa dokumentasi kegiatan strategi branding produk sambel pecel Madiun sebagaimana Gambar 8 dan Gambar 9.

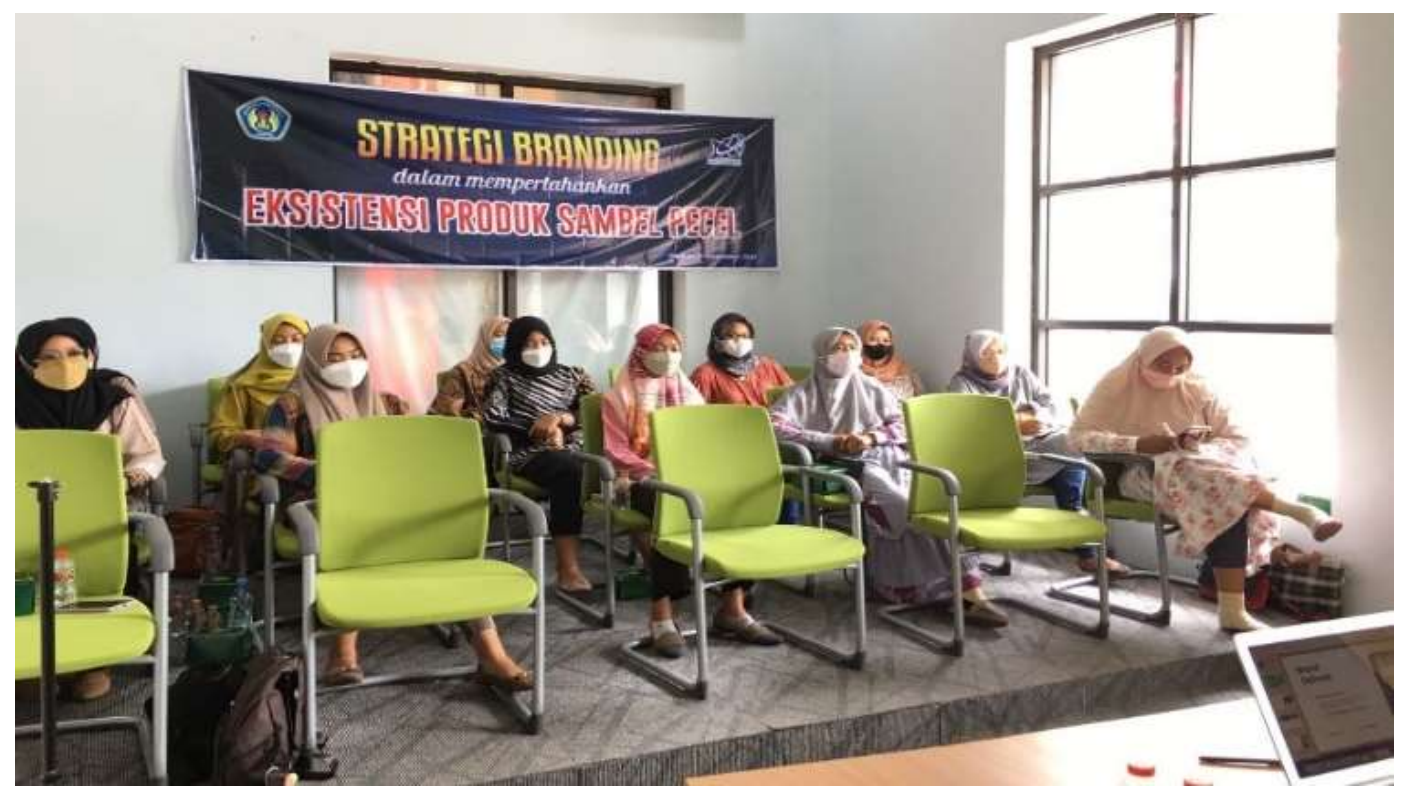

Gambar 9. Peserta workshop strategi branding

Hasil dari pemaparan materi mengenai branding yaitu penjelasan tentang definisi branding dan pentingnya strategi branding dalam mutu penjualan. Selain itu media komunikasi juga berpengaruh pada strategi branding pada sebuah produk, seperti promosi produk di media sosial (Instagram maupun facebook).

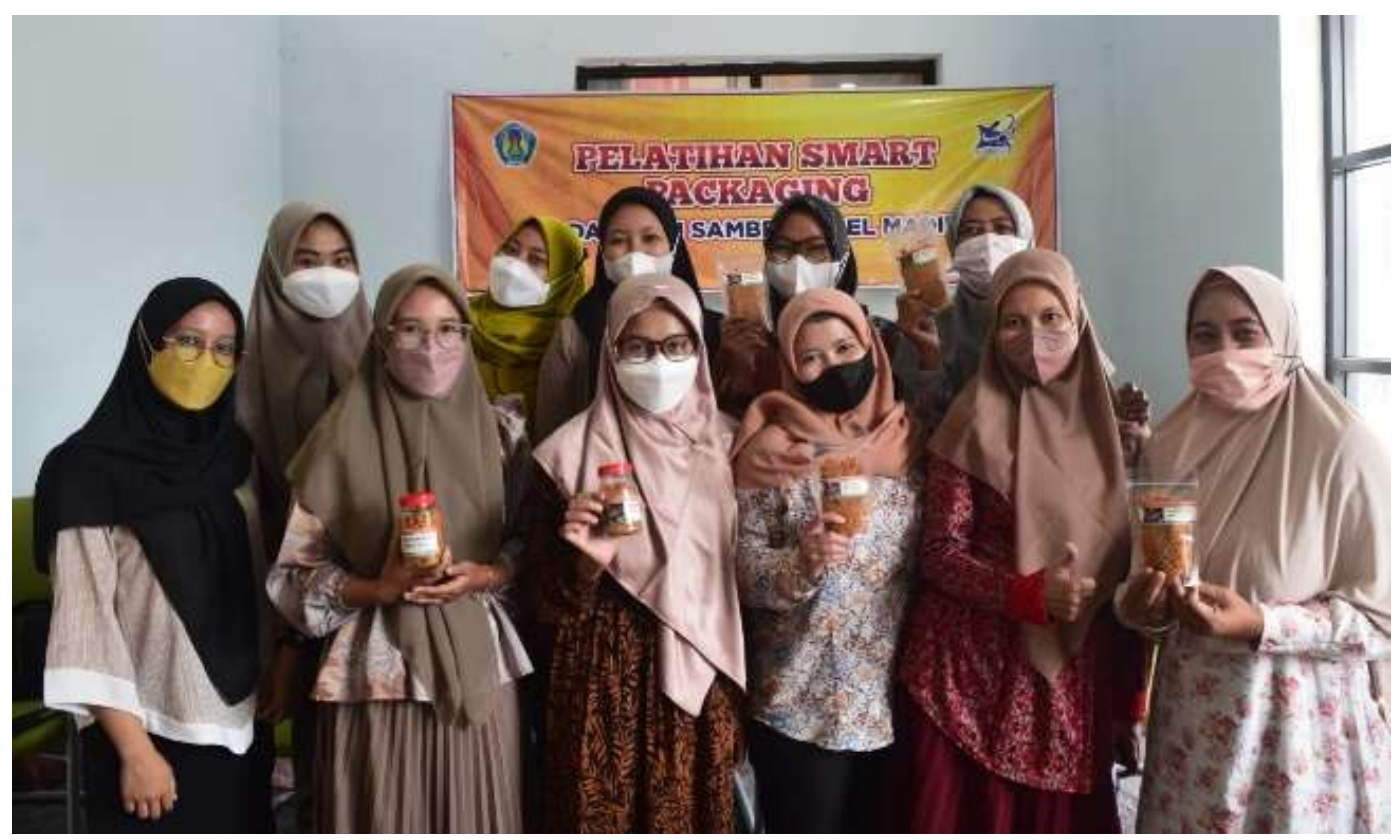

Gambar 10. Foto bersama peserta UMKM Sambel pecel 
Setelah penyampaian materi, tahap selanjutnya adalah tutorial dalam packaging sambel pecel. Packaging sambel pecel dapat menggunakan botol dan plastic vacuum sealer. Adapun hasil dari packaging yang dilakukan oleh para peserta UMKM sambel pecel adalah sebagai berikut:

\section{Kesimpulan}

Di Kota Madiun, sambel pecel merupakan produk unggulan karena banyak nya peminat atau pecinta nasi pecel di sekitaran daerah karasidenan Madiun. Sehingga memungkinkan banyak pelaku UMKM untuk memproduksi sambel pecel untuk dijual dikalangan pasar-pasar tradisional. Para komunitas UMKM sambel pecel di Madiun saat ini masih kurang pengetahuan tentang pentingnya pengaruh King of Brama (packaging, branding, marketing) suatu produk dalam inovasi pengemasan produk sambel pecel secara modern.

Pembekalan ini bertujuan untuk memberikan sosialisasi mengenai inovasi dalam pengemasan branding yang lebih modern kepada para komunitas UMKM sambel pecel Kota Madiun supaya membantu peningkatan omset penjualan selama masa pandemic covid-19. Inovasi pembrandingan ini berupa pengemasan sambel pecel menggunakan cup yang kemudian diberi label brand semenarik mungkin sesuai kriteria masing-masing para komunitas UMKM sambel pecel. Dikarenakan pentingnya inovasi kemajuan dalam sektor makanan maupun bidang ekonomi, maka program ini diharapkan menjadi harapan baik mereka yang ingin berkembang dan memperbaiki metode pemasarannya.

\section{Ucapan Terimakasih}

Kami sampaikan rasa terimakasih pada pihak UMKM Sambel Pecel Madiun selaku peserta kegiatan pengabdian masyarakat, pihak narasumber selaku pmeberi materi branding, marketing dan packaging, serta Universitas PGRI Madiun yang sudah mendukung kegiatan ini.

\section{Referensi}

Luckyta Sari, S., \& Oktovita Sari, P. (2021). Pemberian Merek Dan Kemasan Pada Produk Sambal Pecel Khas Madiun Buatan Bu Windarti. In Jurnal Pengabdian Masyarakat (Vol. 1, Issue 1).

Maulida Sari, C. D., \& Setiyana, R. (2020). Sosialisasi Digital Marketing pada Usaha Mikro Kecil Menengah (UMKM). Jurnal Pengabdian Masyarakat: Darma Bakti Teuku Umar, 2(1), 63. https://doi.org/10.35308/baktiku.v2i1.2050

Anang T.N. (2020). Sukses Bisnis Toko Online. Jakarta: Gramedia Pustaka Utama Kotler, dan Keller. (2012). Manajemen Pemasaran. Edisi 12. Jakarta: Erlangga

Sari, S. L. (2020) Buku Ajar Manajemen Usaha Kecil dan Menengah. Madiun: Unipma Press. 
Sari, I. A. P., dkk.(2019). Produk Olahan Sehat Pecel Sangrai Desa Tulangan.Jurnal Abdimas Adi Buana. Vol 03 . No 1. Diakses pada http://jurnal.unipasby.ac.id/index.php/abdimas/article/view/1929/1740

Zulkarnaen, H.O (2013). "AnalisisStrategi Pemasaran pada Usaha Kecil Menengah (UKM) Makanan Ringan (Studi Penelitian UKM Snack Barokah di Solo)". Fakultas Ekonomis dan Bisnis. Universitas Diponegoro. Semarang 